\title{
Impact of Consumer Loss Aversion on Operations in the Context of Remanufacturing
}

\author{
Bi-feng Liao $\mathbb{D i D}^{1}$ and Bing-zhang Wang $\mathbb{( D D}^{2}$ \\ ${ }^{1}$ School of Economics and Management, Yantai University, Yantai, China \\ ${ }^{2}$ School of Mathematics and Information Sciences, Yantai University, Yantai, China \\ Correspondence should be addressed to Bing-zhang Wang; wbzhyt@163.com
}

Received 14 March 2020; Revised 30 September 2020; Accepted 4 October 2020; Published 19 October 2020

Academic Editor: Michele Scarpiniti

Copyright ( 2020 Bi-feng Liao and Bing-zhang Wang. This is an open access article distributed under the Creative Commons Attribution License, which permits unrestricted use, distribution, and reproduction in any medium, provided the original work is properly cited.

\begin{abstract}
Loss aversion is an important psychological characteristic that has become well supported in finance and marketing. This paper introduces consumer loss aversion into the game model with two substitutable products in a remanufacturing system. The lossaverse consumers gain utility from comparing the price and value dimensions with the superior product. Our model highlights alternative products competition, product selections, and consumption psychology in a remanufacturing environment. The results show that consumer loss aversion has important implications on key decisions in the remanufacturing system. When the manufacturer faces loss-averse consumers, there is a tendency to charge higher prices for two types of products. At the same time, the sales prices increase with the degree of loss aversion. Further analysis reveals that if the manufacturer manipulates consumers with a high probability of purchase, the feature of loss aversion usually benefits him. Our theoretical analyses are proven by numerical computation and some useful conclusions are summarized in this paper.
\end{abstract}

\section{Introduction}

Driven by the regulations around the world devoted to forcing producers to take the responsibility for their end-oflife (EOL) products, researchers are increasingly investigating the Closed-Loop Supply Chain (CLSC) in recent decades [1-3]. In addition to the conventional Forward Supply Chain (FSC), it includes Reverse Supply Chain (RSC) in CLSC. FSC does not account for EOL products. However, RSC manages EOL products in the most environmentally friendly manner possible, which involves activities such as acquisition, collection, and reprocessing-reuse, recycling, or remanufacturing [4-7]. CLSC integrates both the FSC and RSC simultaneously [8,9]. Remanufacturing is the most effective form for EOL product recovery and it is generally accepted that remanufacturing is one important means for establishing resources-saving society [10-13]. Therefore, our paper addresses the concern of the operations in CLSC based on remanufacturing.
Remanufacturing is a process of fully extracting the additional value from EOL products and applies advanced remanufacturing technology to the production of new products. It achieves energy-saving and emission reduction, which greatly benefits the enterprises and the society $[14,15]$. Both Lenovo and Apple Inc. implement Recycling Program. Several successful examples from the industry have already highlighted the high-profit margin for remanufactured products, for instance, Kodak, Xerox, and IBM.

Although a large number of theory studies and practices from the industry at home and abroad indicate that there are great prospects for development in remanufacturing, the decision-making to remanufacture is difficult because there is a great diversity of industry practice and little guidance for remanufacturers to go forward. It is well known that profit is the key point of the operation and the driving force for the development of enterprises. It is affected by many factors. And among all, the market share is of utmost importance [14]. 
This paper aims to provide guidelines for manufacturers to make optimal decision-making. Considering the complex characteristics of the remanufacturing system, we address the following three problems to identify the drives for remanufacturing: (1) consumer perception of price and value dimensions for new and remanufactured products, (2) consumer preference for the two types of products, and (3) the influence of consumer loss aversion on operations.

\subsection{Price and Value Dimensions of New and Remanufactured Products. Remanufacturing has been identified to be the most effective way to minimize the consumption of energy and raw materials, leave less air pollution, and reduce waste disposal treatments [16]. The remanufactured product is a new alternative environment-friendly product. The low cost and low price are their competitive advantages. Although remanufactured products affect the market share of the primary new products, it may be an important path to realize the sustainable development. This issue is discussed ex- haustively in this paper. The results show that remanu- facturing is a new growth point.}

\subsection{Consumer Preference for New and Remanufactured} Products. The raw materials for remanufacturing are EOL products. It is no surprise that consumers perceive new products to be of a higher quality standard and they usually have lower valuation for remanufactured products. Before purchasing or using remanufactured products, consumers are often uncertain about the actual performance and physical reliability and hold the idea that new products have better properties. As such, if the new product is available, it is taken for granted that the new product is the best choice. Consumers can clearly distinguish new and remanufactured products. Their willingness to pay (WTP) for remanufactured products is obviously lower than that for new ones. WTP difference plays a significant role in demands for both products and supply chain performance.

1.3. Consumer Loss Aversion. The important characteristics of loss aversion are that people are reluctant to accept losses and tend to choose avoiding losses. It is well supported in finance and marketing and has extensive and profound influence $[17,18]$. As loss aversion obviously exists in reality, it attracts researchers' interests significantly [19-21]. In the case of utilizing remanufactured products, most customers are often uncertain about the product properties. It is, therefore, of no surprise that the consumers usually have a lower valuation for remanufactured products. The instinct that consumers as far as possible avoid losses leads them to hardly make purchase decisions for remanufactured products and significantly affects the operation performance of CLSC.

The outline of our paper is as follows. We provide an exhaustive literature review in Section 2. In the next section, we lay out the features of the market demand. Section 4 presents the game models and obtains the equilibrium. Then, numerical examples and environmental assessment are presented in Sections 5 and 6, respectively. Finally, our paper briefly concludes in Section 7 and offers some possible directions for future work in this area.

\section{Relevant Literature}

Our paper is closely related to the following two research fields in CLSC: consumer preference and remanufacturing. At present, a variety of articles are carried out to investigate the remanufacturing profitability from the perspective of the manufacturer. Ferguson and Toktay [22] investigate remanufacturing and collection decisions to derive conditions under which strategy is profitable. In a stochastic demand setting, Kaya [23] considers the decision-making with the incentive strategy and product remanufacturing. According to a variety of different parameters, the impacts on system performance are taken into account in the paper. Chen and Chang [24] present several game models to identify the economic benefits of the remanufacturing system. Pietro and Georges [25] develop CLSC game models to investigate the operational performance. Mitra [26] develops theoretical models to show that the profit is always higher in the remanufacturing setting. Pietro [27] develops incentive games to investigate product recycling and economic benefits. Raz et al. [28] investigate the economic, environmental, and social impact of remanufacturing.

Interestingly, all these articles concentrate on the strategic research of the remanufacturing system under the general concept of value. Due to the imperfection of the remanufactured products, we cannot easily measure their value in common sense. Atasu et al. [14] introduce consumer WTP to study the profitability of the remanufacturing system. Given that consumer WTP for new and remanufactured products is different, Ferrer and Swaminathan [29] propose game models with differentiated prices for them. Agrawal et al. [30] investigate that the existence of remanufactured products has a direct influence on the consumers' perceived value for new ones. Abbey et al. [31] discuss the optimal decision-making in CLSC considering consumer preferences. They reveal that the original equipment manufacturer can reap high profits through making different prices for them. Gan et al. [32] reveal that the cognition and attitudes to remanufactured products play an important role in enhancing the profit of players. Kovach et al. [33] present a salesforce incentive model to investigate the salesforce incentives and the enterprise's decisionmaking. Ma et al. [34] introduce consumer WTP to investigate pricing and recycling strategies in CLSC. Tang et al. [35] conduct a full analysis to examine the impacts of pricing and warranty decisions on profitability and consumer surplus in the context of remanufacturing. Ramírez et al. [36] propose economic models to demonstrate the economic outputs and environmental impacts.

All these papers mentioned above mainly investigate the performance in CLSC operations considering loss-neutral consumers and they ignore the psychological characteristics of loss aversion. Brooks and Zank [37] demonstrate the behavior of consumers in the market and point out that most consumers are loss averse. The analysis and consequences of 
consumer loss aversion have become an important part of the economic applications [38]. There is, as mentioned above, a growing number of research works devoted to extending their research in the loss aversion context. Heidhues and Koszegi [39] study the choice process of loss-averse consumers. Kotonya et al. [40] propose a model describing the consumer choice impact of loss aversion. They point out that cheaper product is more likely to attract loss-averse consumers. Kim and Lee [41] investigate the effects of consumer loss aversion on enterprise's decisions. Antonia [42] identifies the production management and pricing strategies when a retailer faces loss-averse consumers. Fabrizi et al. [43] present game models to show the great influence of reference dependence on consumer preferences. März [44] proposes a model to investigate the effects of persuasive advertising targeted at loss-averse consumers. Ghesla et al. [45] conduct a field experiment to evaluate the effectiveness proenvironmental incentives in a loss frame.

Inspired by these findings, we analyze the strategic behavior of a profit-maximizing manufacturer facing lossaverse consumers. We contribute to the research by providing a new perspective and method to the remanufacturing system and the main concern on the factors of our research is associated with the demand side. The combination of these factors is embodied in three aspects. First, we consider the value dimension of products. Second, we capture the WTP difference for new and remanufactured products. Finally, we analyze the influence of consumer loss aversion on the decision-making. So far as we know, this is the first paper that integrates the above three factors simultaneously in a remanufacturing context.

\section{Model Description}

We illustrate the game between the consumers and the manufacturer in Figure 1. Based on consumer preference, a consumer first forms his valuation and learns his reference point. Then, the manufacturer charges differential prices for two types of products. Finally, the consumer makes a choice and hence the market demand is realized.

Now assume that the market capacity is normalized to one and it is uniformly distributed on $[0,1]$. Consumers are classified into two basic categories depending on their individual psychological characteristics: the most common type of loss-neutral consumers and rarely mentioned type of loss-averse consumers. We use $N$ and $L$ to indicate the two types of consumers, respectively.

Consider an OEM who manufactures remanufactured products along with original new products. The two types of products are sold in the same market and we further hypothesise that they are not available for sale elsewhere. The two types of products are partially substitutable and consumer valuations are different for them. Consumers are free to make the choice between the two types of products.

Case 1. Loss-neutral consumers.

We first consider the market with the loss-neutral consumers and take this as a benchmark scenario. Our goal is to help identify the parameters that will impact decisionmaking.

Suppose that consumers distinguish between new and remanufactured products. The WTP is subjected to uniform distribution on $[0,1]$. In general, consumers perceive remanufactured products as having less quality. Therefore, when consumers are loss-neutral, the WTP for new products is $v$ and that for remanufactured products is $\theta v$, where $0<\theta<1$. That is, the perceived value of remanufactured products to consumers is not higher than that of new ones.

This paper describes consumers' preferences with utility functions $u_{n}$ and $u_{r}$. If the selling price of a new product is $p_{n}$, a loss-neutral consumer gets net utility $u_{n}=v-p_{n}$. And if the selling price of a remanufactured product is $p_{r}$, a loss-neutral consumer gets net utility $u_{r}=\theta v-p_{r}$. The net utility is equal to zero when the loss-neutral consumer does not purchase any products. Consumer utility is the standard notion in economics, which depends only on the absolute outcomes.

Consumers tend to choose to buy new products if $u_{n}>u_{r}$ and $u_{n}>0$. Otherwise, consumers will switch to remanufactured products if $u_{r}>0$. We illustrate the utility function in Figure 2.

Then, consumer preference is summarized in the following lemma.

Lemma 1. In the loss-neutral benchmark,

(a) consumers with $v \in\left[\left(\left(p_{n}-p_{r}\right) /(1-\theta)\right), 1\right]$ plan to purchase new products

(b) consumers with $v \in\left[\left(p_{r} / \theta\right),\left(\left(p_{n}-p_{r}\right) /(1-\theta)\right)\right)$ plan to purchase remanufactured products

(c) consumers with $v \in\left[0,\left[p_{r} / \theta\right)\right)$ plan to purchase nothing

We obtain the demand functions for two types of products are as follows $[15,35,46]$ :

$$
\begin{aligned}
& q_{n}^{N}=1-\frac{p_{n}-p_{r}}{1-\theta}, \\
& q_{r}^{N}=\frac{\left(p_{n}-p_{r}\right)}{(1-\theta)}-\frac{p_{r}}{\theta} .
\end{aligned}
$$

Case 2. Loss-averse consumers.

Loss-averse can explain the anomalous behavior according to classical economic theory and researchers recently show great interest in the market implications of nonstandard consumer behavior. Behavioral economics has accumulated abundant evidence of reference dependence with loss aversion. This paper assumes the reference dependence is determined endogenously, which is given by the rational expectations [47]. This paper introduces reference dependence by considering products sequentially. When consumers value the later product, the new one-the first product they are willing to purchase-may become the reference point. It is known to all that new products are enjoying broad market acceptance today, and consumers generally prefer new products to remanufactured products. And so, it is reasonable to take the new product 


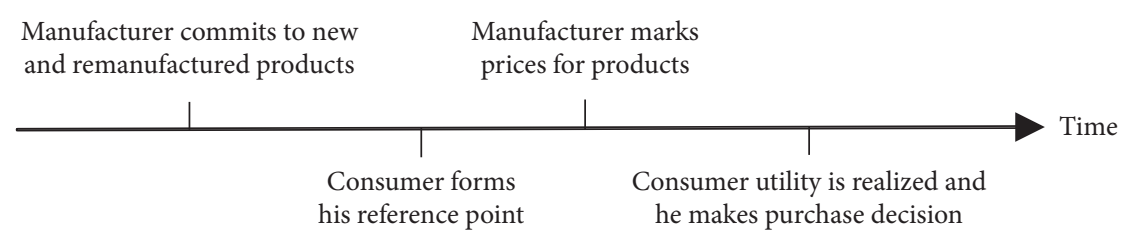

Figure 1: The timing of the game.

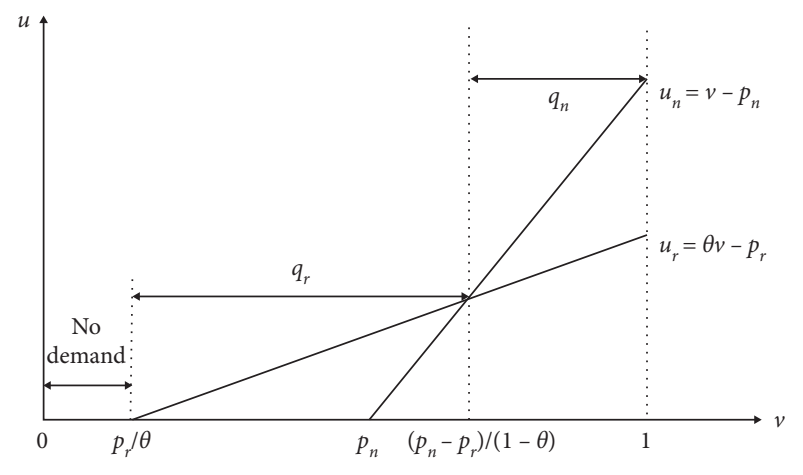

Figure 2: The loss-neutral consumer utility.

as a reference point. We employ utility as the carrier of loss aversion. This view is adopted in Tversky and Kahneman [48], Hardie et al. [49], Kobberling and Wakker [50], Horst and Peter [20], and so on.

It is obviously different from the standard loss-neutral consumers. The total utility of loss-averse consumers comes in two additive parts. First is the intrinsic consumer surplus when a consumer buys the product. Second is the gain-loss utility when consumers compare the actual outcome with rational expectations. It captures reference dependence and loss aversion. As such, if a consumer purchases a new product at a price $p_{n}$, the consumer utility is

$$
u_{n}=v-p_{n}
$$

If a consumer purchases the remanufactured product, the preferred new product is the reference point of the transaction. The utility is derived from the reference point. Suppose consumers measure gains and losses with price and value dimensions separately. As consumers value the remanufactured products less than the new ones, they suffer a loss in the product dimension. On the other hand, manufacturers always charge a lower price for a remanufactured product than a new one and consumers benefit from the price dimension. Therefore, the consumer total utility of purchasing a remanufactured product is as follows:

$$
u_{r}=\theta v-p_{r}+\mu(\theta v-v)+\mu\left(p_{n}-p_{r}\right)
$$

where

$$
\mu\left(x-x_{0}\right)= \begin{cases}x-x_{0}, & x \geq x_{0}, \\ \lambda\left(x-x_{0}\right), & x<x_{0}\end{cases}
$$

is gain-loss utility [51]. The parameter $\lambda$ represents the degree of consumer loss aversion and $\lambda>1$ captures the characteristic that makes consumers more concerned about losses than gains.

Therefore, consumers total utility of purchasing remanufactured products is given by

$$
u_{r}=\theta v-p_{r}-\lambda(v-\theta) v+\left(p_{n}-p_{r}\right) \text {. }
$$

Consumers are willing to buy new products if $u_{n}>0$ and $u_{n}>u_{r}$. Otherwise, consumers will switch to remanufactured products if $u_{r}>u_{0}$, where $u_{0}$ is the utility of purchasing nothing for loss-averse consumers. The utility function is illustrated in Figure 3.

In order to describe the consumer preference associated with the prices of the two types of products, the value discount and consumer loss aversion, we present a useful lemma as follows.

Lemma 2. In the loss-averse situation,

(A) consumers with $v \in\left[2\left(p_{n}-p_{r}\right) /((1-\theta)(1+\lambda)), 1\right]$ plan to purchase new products

(B) consumers with $v \in\left[\left(2 p_{r} /(\theta(1+\lambda))\right),\left(2\left(p_{n}-p_{r}\right) /\right.\right.$ $(1+\lambda)(1-\theta)))$ plan to purchase remanufactured products

(C) consumers with $v \in\left[0,\left(2 p_{r} / \theta(1+\lambda)\right)\right)$ plan to purchase nothing

Similarly, the demand functions can be written as

$$
\begin{aligned}
q_{n}^{L} & =1-\frac{2\left(2 p_{n}-p_{r}\right)}{(1-\theta)(1+\lambda)} \\
q_{r}^{L} & =\frac{2\left(2 p_{n}-p_{r}\right)}{(1-\theta)(1+\lambda)}-\frac{2 p_{r}}{\theta(1+\lambda)} .
\end{aligned}
$$

\section{Analysis Results}

Recall that consumers are reference dependent and lossaverse. The market share of the two types of products, manufacturer decision-making process, and equilibrium analysis are presented next.

\subsection{Market Share}

Proposition 1. If the manufacturer keeps the prices fixed, then 


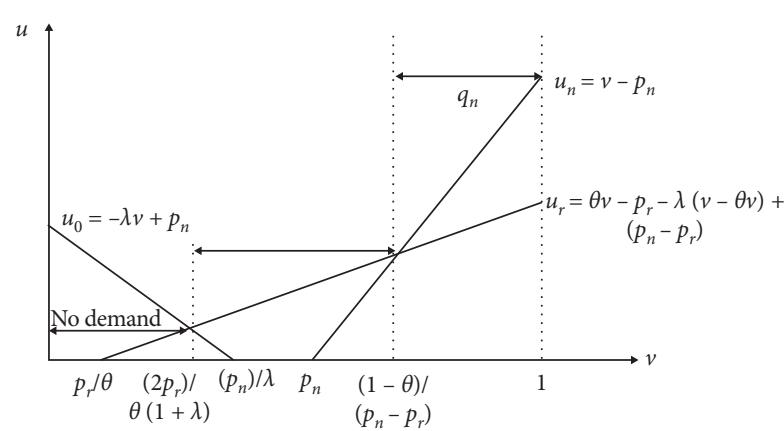

FIgURE 3: The loss-averse consumer utility.

(1) some additional market share is picked up under loss aversion

(2) there is a greater demand for new products in the loss-averse situation than in the loss-neutral benchmark

Proof. It is easy to see that $(2 /(1+\lambda))<1$ since $\lambda>1$. Therefore, we have

$$
\begin{aligned}
\frac{2 p_{r}}{\theta(1+\lambda)}<\frac{p_{r}}{\theta}, \\
\frac{2\left(p_{n}-p_{r}\right)}{(1-\theta)(1+\lambda)}<\frac{\left(p_{n}-p_{r}\right)}{(1-\theta)}, \\
q_{n}^{L}=1-\frac{2\left(p_{n}-p_{r}\right)}{(1-\theta)(1+\lambda)}>q_{n}^{N}=1-\frac{p_{n}-p_{r}}{1-\theta} .
\end{aligned}
$$

This concludes the proof.

Proposition 1 shows that loss-neutral consumers do not identify any losses when purchasing nothing. But if loss-averse consumers purchase nothing, they feel a loss compared to getting a product. This leads to increased market share.

Due to the uncertainty factors which influence the perception of remanufactured products, loss-averse consumers prefer new ones. As such, there is a greater demand for new products in the loss-averse situation than in the lossneutral benchmark.

4.2. OptimalDecisions. The manufacturer's profit is given by the following equation:

$$
\max _{p_{n}, p_{r}} \pi=\left(p_{n}-c_{n}\right) q_{n}+\left(p_{r}-c_{r}\right) q_{r} .
$$

According to the first-order conditions, we obtain the following results.

Proposition 2. When consumers are loss-neutral, the strategic equilibrium and profit are given by

$$
\begin{aligned}
& q_{n}^{N}=\frac{1-\theta-c_{n}+c_{r}}{2(1-\theta)}, \\
& q_{r}^{N}=\frac{\theta c_{n}-c_{r}}{2 \theta(1-\theta)}, \\
& p_{n}^{N}=\frac{1+c_{n}}{2}, \\
& p_{r}^{N}=\frac{\theta+c_{r}}{2}, \\
& \pi^{N}=\frac{1-2 c_{n}}{4}+\frac{c_{r}^{2}}{4 \theta}+\frac{\left(c_{n}-c_{r}\right)^{2}}{4(1-\theta)} .
\end{aligned}
$$

Proposition 3. The manufacturer's optimal decisions and profit in the loss-averse situation are given by

$$
\begin{aligned}
& q_{n}^{L}=\frac{t-\theta t-c_{n}+c_{r}}{2 t(1-\theta)}=\frac{1}{2}-\frac{c_{n}-c_{r}}{2 t(1-\theta)}, \\
& q_{r}^{L}=\frac{\theta c_{n}-c_{r}}{2 \theta t(1-\theta)}, \\
& p_{n}^{L}=\frac{t+c_{n}}{2}, \\
& p_{r}^{L}=\frac{\theta t+c_{r}}{2}, \\
& \pi^{L}=\frac{t-2 c_{n}}{4}+\frac{c_{r}^{2}}{4 \theta t}+\frac{\left(c_{n}-c_{r}\right)^{2}}{4 t(1-\theta)},
\end{aligned}
$$

where $t=((1+\lambda) / 2)>1$.

4.3. Equilibrium Analysis. Having discovered the results of the game equilibrium of the two cases, we are interested in analyzing the impact of consumer loss aversion. The following propositions are derived from the equilibrium of the two scenarios.

Proposition 4. The manufacturer charges a higher price for new products under loss aversion than loss-neutrality and the price goes up with consumer loss aversion.

Proof

$$
\begin{aligned}
p_{n}^{L}-p_{n}^{N} & =\frac{t+c_{n}}{2}-\frac{1+c_{n}}{2}=\frac{t-1}{2}>0, \\
\frac{\partial p_{n}^{L}}{\partial \lambda} & =\frac{\partial p_{n}^{L}}{\partial t} \frac{\partial t}{\partial \lambda}=\frac{1}{4}>0 .
\end{aligned}
$$

We compute the difference in their prices under consumer loss aversion and loss-neutrality and find that they are positive for all parameter values under our assumptions. 
Thus, we have the result that the manufacturer charges a higher price in the loss-averse situation.

We differentiate $p_{n}^{L}$ with respect to $\lambda$ and check the sign. It suffices to demonstrate that the price goes up with consumer loss aversion.

From Proposition 4, we can obtain the following corollary.

Corollary 1. The scale of price dispersion for new products widens with consumer loss aversion.

Proposition 5. A manufacturer charges a higher price for remanufactured products in the loss-averse situation. And the price increases with the degree of consumer loss aversion.

Proof

$$
\begin{aligned}
p_{r}^{L}-p_{r}^{N} & =\frac{\theta t+c_{r}}{2}-\frac{\theta+c_{r}}{2}=\frac{\theta(t-1)}{2}>0, \\
\frac{\partial p_{r}^{L}}{\partial \lambda} & =\frac{\partial p_{r}^{L}}{\partial t} \frac{\partial t}{\partial \lambda}=\frac{\theta}{4}>0 .
\end{aligned}
$$

Propositions 4 and 5 show that consumers are expected to purchase a product in the loss-averse situation and the manufacturer would charge higher prices for the two types of products.

Proposition 6. Consumer loss aversion boosts sales of new products and the sales of new products are larger under loss aversion than loss neutrality. But it is the contrary for the remanufactured products.

Proof. It is similar to Proposition 5.

Proposition 6 points out that consumers might pull their choices out of the remanufacturing sales market to avoid incurring losses and purchase new products instead. Consequently, the market share of the remanufactured ones will be reduced sharply. This gives new products the opportunity to grab a big market share.

\section{Numerical Results}

To get a better understanding of our analytical findings and complement them with new insights under such two different consumer markets, we next discuss the equilibrium resulting in profit using numerical experiments.

Countless instances indicate that consumer WTP and cost savings may vary with product features $[4,14,31,52,53]$.

We obtain the estimates of $\lambda$ in various scenarios. A value of $\lambda$ greater than one shows that consumers are loss-averse. And the greater the value, the more the loss aversion $[42,49,54]$.

Based on the survey data of the remanufacturing markets and related literature $[46,55,56]$, we give the parameter values as follows: $c_{n}=0.4, c_{r}=0.2, \theta=0.6, \lambda=2$. The red curve with diamonds and the black curve with asterisks in

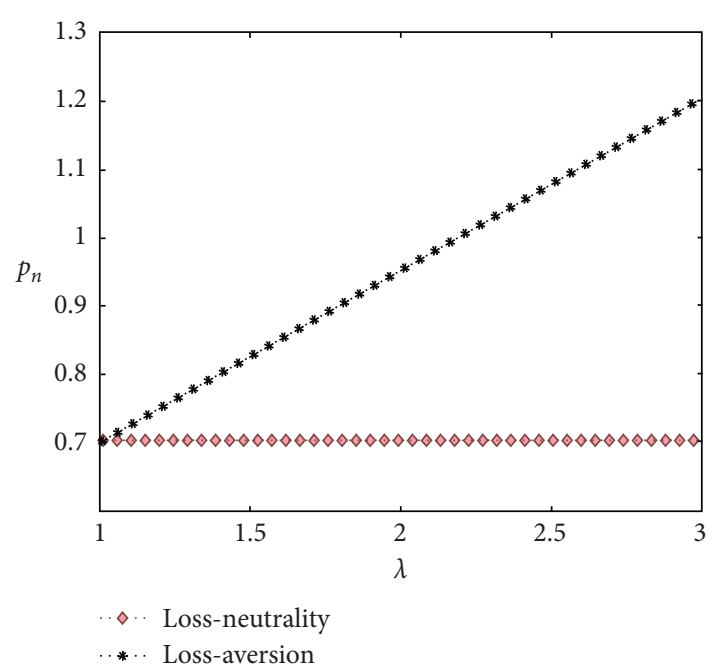

Figure 4: Impact of $\lambda$ on $p_{n}$.

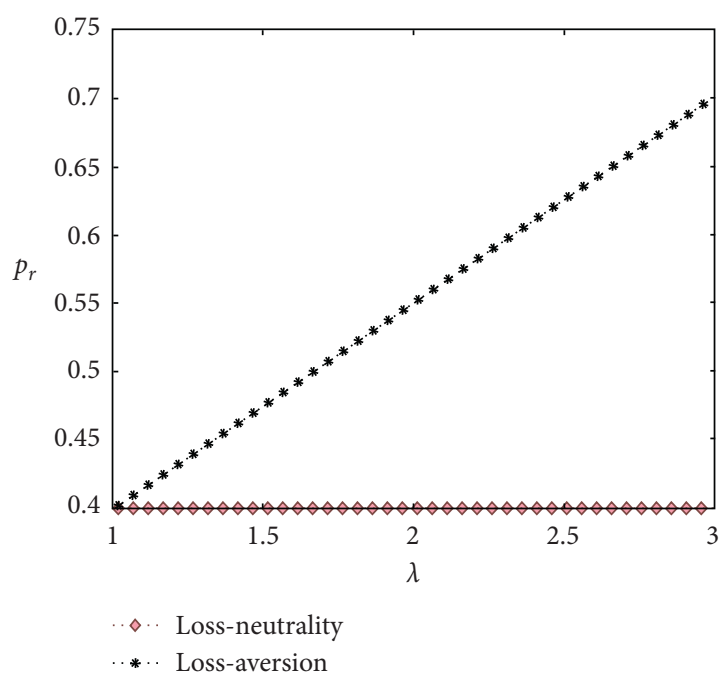

Figure 5: Impact of $\lambda$ on $p_{r}$.

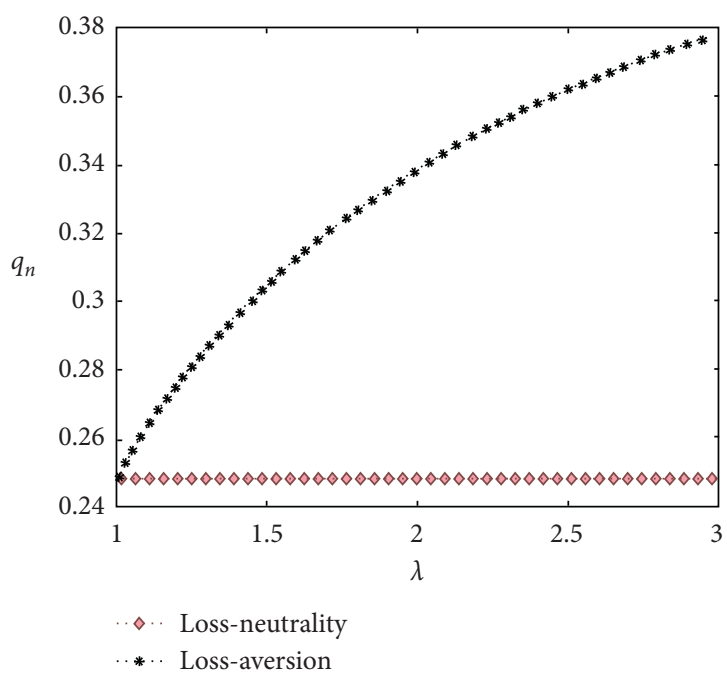

Figure 6: Effect of $\lambda$ on $q_{n}$. 


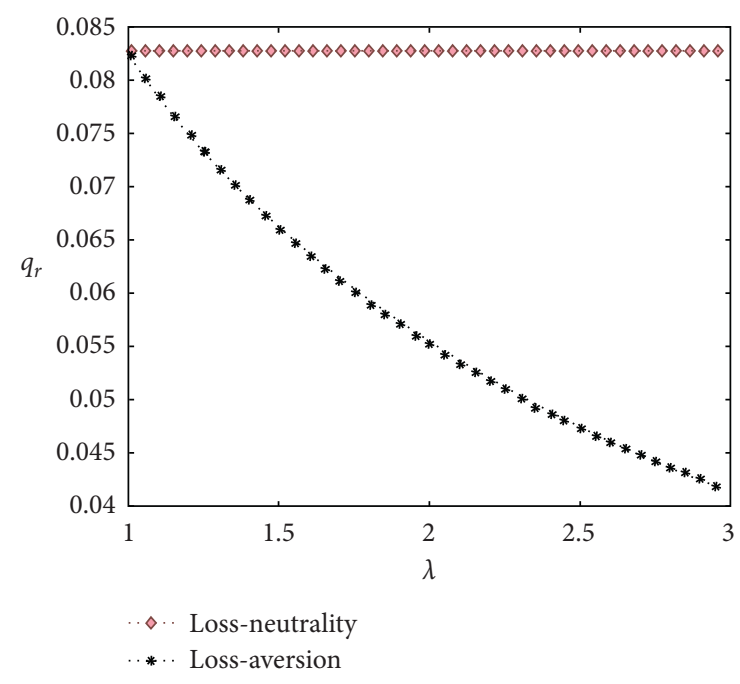

FIgURE 7: Effect of $\lambda$ on $q_{r}$.

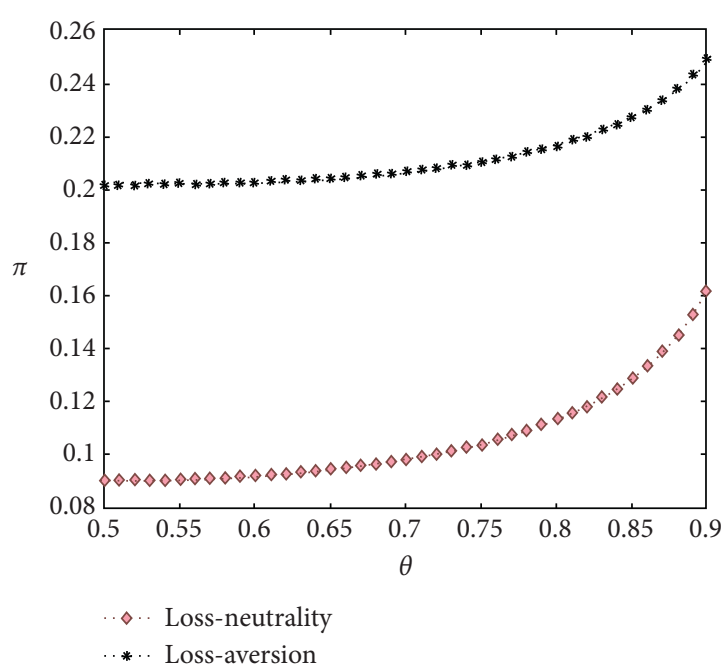

Figure 8: Effect of $\theta$ on $\pi$.

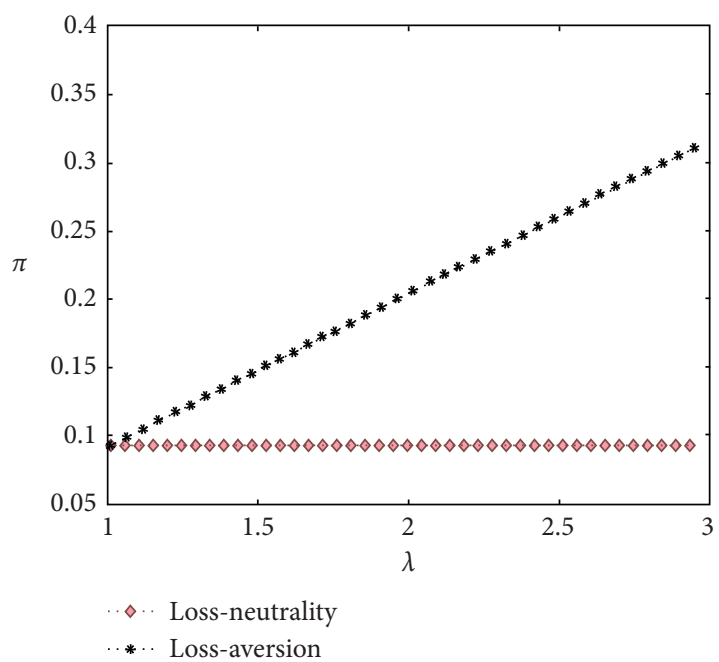

Figure 9: Effect of $\lambda$ on $\pi$.

price advantage for remanufactured and new products, respectively. This makes it easier for the manufacturer to seize the chance to charge a higher price and the operation performance also increases.

\section{Environmental Performance}

Remanufacturing is generally perceived as an environmentally friendly management option for EOL products. When compared to manufacturing, remanufacturing itself uses less energy and reduces environmental pollution. Here, the total environmental impacts of CLSC in these two cases enter into our discussion.

In the whole lifecycle, the process of production, use, recycling, and remanufacturing all have a degree of environmental impact. We assume that the environmental impact factors borne by each unit of new products are $N$ and of remanufactured ones are $R$. As remanufactured products are green products, we may wish to set up $R<N$. 


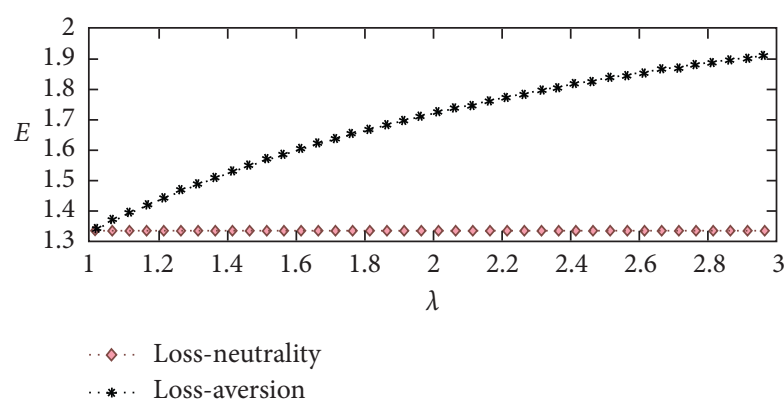

Figure 10: Effect of $\lambda$ on environment $(N=5$ and $R=1)$.

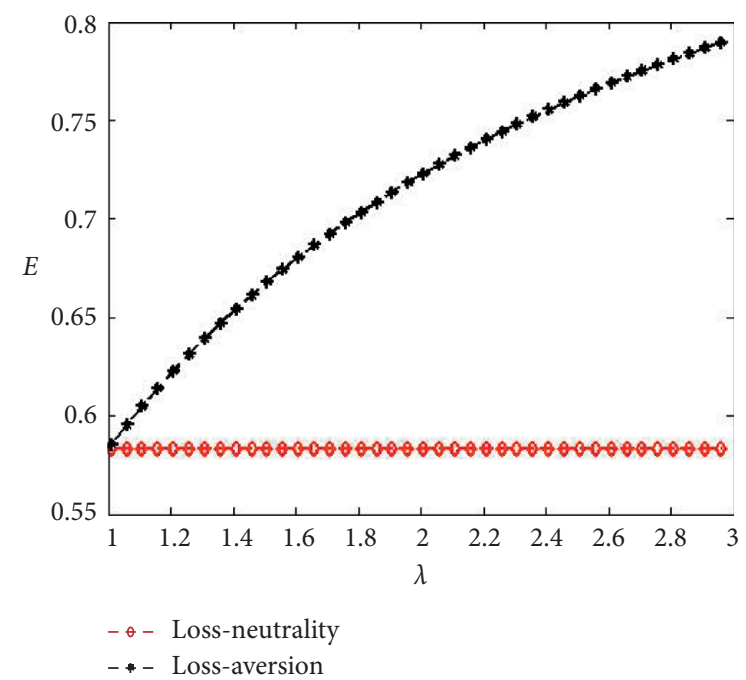

FIgURE 11: Effect of $\lambda$ on environment $(N=2$ and $R=1)$.

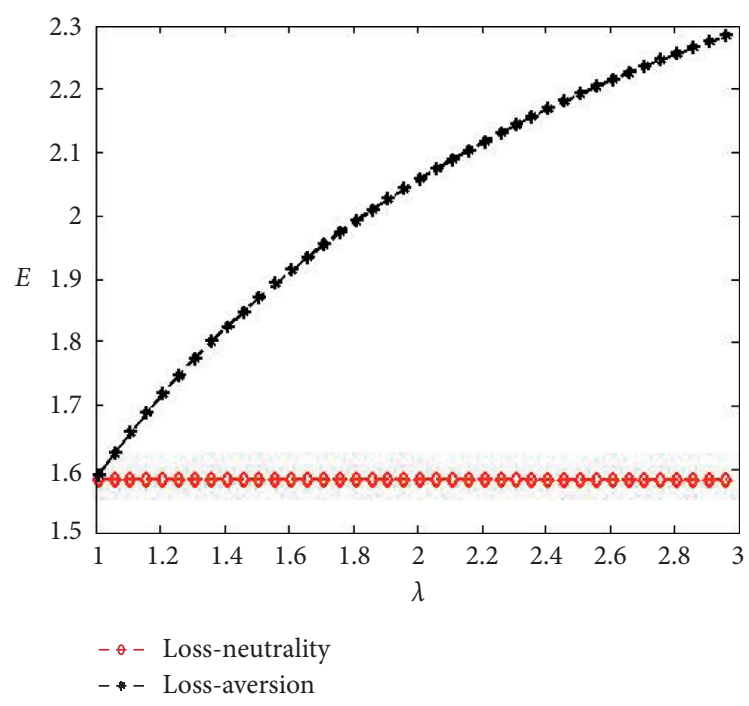

FIgURE 12: Effect of $\lambda$ on environment $(N=6$ and $R=1)$.

Figures 10-12 illustrate the environmental impact of the two consumer markets with different parameters.

As can be seen from Figures 10-12, the environmental effect of consumer loss aversion is negative. This is because consumer loss aversion brings about more new production and hence an increase in the total energy. What is important is that the relative energy consumption per unit of product decreases and this growth in the total energy is sustainable. As the development of remanufacturing lies largely on the snatch of the incumbent market and the exploitation of the new market, it is necessary to mitigate consumer uncertainty and consumer loss aversion that is depressing demand for remanufacturing products. To achieve a "win-win" situation, the manufacture will more likely adopt strategies to attract consumers to buy remanufactured products, such as fixedprice subsidy, advertising, and promotion.

\section{Concluding Remarks}

The "loss aversion" theory is one of the representative theories about behavioral finance. It accounts for a variety of economic phenomena which includes the equity premium puzzle and important economic markets. This paper introduces consumer loss aversion to investigate the players' decision-making in CLSC with remanufacturing. We combine the products competition, WTP difference, and consumer loss aversion in our model. This research shows that if consumers cannot obtain the product what they expect, they feel they suffer a loss and are very sensitive to this loss. This not only increases consumer WTP, but also boosts the immediate demand for new products. Thus, consumer loss aversion can be used to exploit future market size and a higher degree of loss aversion leads to higher profit. The results in this paper provide a useful reference for remanufacturers arousing consumer loss aversion to reap economic benefits.

This paper is contributing some insights into decisionmaking when faced with loss-averse consumers; however, there are several aspects that are not taken into account. Our model shows better operational performance and worse environmental performance and one natural possibility would be to consider an environmental regulation. In our model, new and remanufactured products are in plentiful supply in the market. In view of the supply of remanufactured products, it is bounded by the number of EOL products recycled from consumers. Therefore, remanufactured products facing supply constraints would seem to be more appropriate in CLSC with remanufacturing. Loosening the restriction that consumers are willing to purchase new products can also bring about somewhat different explanations. These hypotheses are more objective and in line with reality, and they are exciting avenues for research. Similarly, one could consider that manufacturers are loss-averse. As to the situation with loss aversion of both consumer and manufacturer, it will be more complicated and therefore be completed in the follow-up study. Finally, we assume consumers prefer new products as reference points in this paper. The measures to improve consumer acceptance of remanufactured products, as well as the alternative new products as reference points to remanufactured products, are also potentially interesting extensions. All the possible cases considered may come to entirely different conclusions. This provides a 
new insight for the following study and plays a guiding role in remanufacturing practice.

\section{Data Availability}

All data, models, and codes generated or used during the study are included within the article.

\section{Conflicts of Interest}

The authors declare that they have no conflicts of interest.

\section{Acknowledgments}

This work was supported by the National Natural Science Foundation of China (Grant no. 71672166) and Shandong Social Science Planning Project (Grant no. 20CSDJ10).

\section{References}

[1] M. Fleischmann, P. Beullens, J. M. Bloemhof-Ruwaard, and L. N. Van Wassenhove, "The impact of product recovery on logistics network design," Production and Operations Management, vol. 10, no. 2, pp. 156-173, 2001.

[2] V. D. R. Guide, T. P. Harrison, and L. N. Van Wassenhove, "The challenge of closed-loop supply chains," Interfaces, vol. 33, no. 6, pp. 3-6, 2003.

[3] K. Govindan, H. Soleimani, and D. Kannan, "Reverse logistics and closed-loop supply chain: a comprehensive review to explore the future," European Journal of Operational Research, vol. 240 , no. 3, pp. $603-626,2015$

[4] M. Radhi, Impact of Quality Grading and Uncertainty on Recovery Behaviour in a Remanufacturing Environment, University of Windsor, Windsor, Canada, 2012.

[5] R. Bhattacharya, A. Kaur, and R. K. Amit, "Price optimization of multi-stage remanufacturing in a closed loop supply chain," Journal of Cleaner Production, vol. 186, pp. 943-962, 2018.

[6] Y. Wang, Z. Wang, B. Li, Z. Liu, X. Zhu, and Q. Wang, "Closed-loop supply chain models with product recovery and donation," Journal of Cleaner Production, vol. 227, pp. 861876, 2019.

[7] L. Yang, Y. Hu, and L. Huang, "Collecting mode selection in a remanufacturing supply chain under cap-and-trade regulation," European Journal of Operational Research, vol. 287, no. 2, pp. 480-496, 2020.

[8] S. Dowlatshahi, "Developing a theory of reverse logistics," Interfaces, vol. 30, no. 3, pp. 143-155, 2000.

[9] V. D. R. Guide and L. N. van Wassenhove, "OR FORUM-the evolution of closed-loop supply chain research," Operations Research, vol. 57, no. 1, pp. 10-18, 2009.

[10] G. Ferrer, D. Clay Whybark, and C. M. Dalton, "From garbage to goods: successful remanufacturing systems and skills," Business Horizons, vol. 43, no. 6, pp. 55-64, 2000.

[11] V. D. R. Guide, "Production planning and control for remanufacturing: industry practice and research needs," Journal of Operations Management, vol. 18, no. 4, pp. 467-483, 2000.

[12] A. L. Larson, E. O. Teisberg, and R. R. Johnson, "Sustainable business: opportunity and value creation," Interfaces, vol. 30, no. 3, pp. 1-12, 2000.

[13] Z. Zhang, B. Gong, J. Tang, Z. Liu, and X. Zheng, “The joint dynamic green innovation and pricing strategies for a hybrid system of manufacturing and remanufacturing with carbon emission constraints," Kybernetes, vol. 48, no. 8, pp. 1699-1730, 2019.

[14] A. Atasu, M. Sarvary, and L. N. Van Wassenhove, "Remanufacturing as a marketing strategy," Management Science, vol. 54, no. 10, pp. 1731-1746, 2008.

[15] Z. Wang, Y. Wang, Z. Liu, J. S. Cheng, and X. T. Chen, "Strategic management of product recovery and its environmental impact," International Journal of Production Research, 2020.

[16] S. V. Nagalingam, S. S. Kuik, and Y. Amer, "Performance measurement of product returns with recovery for sustainable manufacturing," Robotics and Computer-Integrated Manufacturing, vol. 29, no. 6, pp. 473-483, 2013.

[17] D. Kahneman and A. Tversky, "Prospect theory: an analysis of decision under risk," Econometrica, vol. 47, no. 2, pp. 263-291, 1979.

[18] E. C. Yurewicz, F. Matsuura, and K. S. Moghissi, "Loss aversion and individual characteristics," Environmental and Resource Economics, vol. 49, no. 4, pp. 573-596, 2011.

[19] U. Schmidt and H. Zank, "What is loss aversion?" Journal of Risk and Uncertainty, vol. 30, no. 2, pp. 157-167, 2005.

[20] Z. Horst and B. Peter, "Loss averse behavior," Journal of Risk and Uncertainty, vol. 31, no. 3, pp. 301-325, 2005.

[21] A. Tversky and D. Kahneman, "Loss aversion in riskless choice: a reference-dependent model," The Quarterly Journal of Economics, vol. 106, no. 4, pp. 1039-1061, 1991.

[22] M. E. Ferguson and L. B. Toktay, "The effect of competition on recovery strategies," Production and Operations Management, vol. 15, no. 3, pp. 351-368, 2010.

[23] O. Kaya, "Incentive and production decisions for remanufacturing operations," European Journal of Operational Research, vol. 201, no. 2, pp. 442-453, 2010.

[24] J.-M. Chen and C.-I. Chang, "The economics of a closed-loop supply chain with remanufacturing," Journal of the Operational Research Society, vol. 63, no. 10, pp. 1323-1335, 2012.

[25] D. G. Pietro and Z. Georges, "A two-period game of a closedloop supply chain," European Journal of Operational Research, vol. 232, no. 1, pp. 22-40, 2014.

[26] S. Mitra, "Models to explore remanufacturing as a competitive strategy under duopoly," Omega, vol. 59, pp. 215-227, 2015.

[27] D. G. Pietro, "Closed-loop supply chain coordination through incentives with asymmetric information," Annals of Operations Research, vol. 253, pp. 133-167, 2017.

[28] G. Raz, A. Ovchinnikov, and V. Blass, "Economic, environmental and social impact of remanufacturing in a competitive setting," IEEE Transactions on Engineering Management, vol. 64, no. 4, pp. 476-490, 2017.

[29] G. Ferrer and J. M. Swaminathan, "Managing new and differentiated remanufactured products," European Journal of Operational Research, vol. 203, no. 2, pp. 370-379, 2010.

[30] V. V. Agrawal, A. Atasu, and K. van Ittersum, "Remanufacturing, third-party competition, and consumers' perceived value of new products," Management Science, vol. 61, no. 1, pp. 60-72, 2015.

[31] J. D. Abbey, J. D. Blackburn, and D. R. Guide, "Optimal pricing for new and remanufactured products," Journal of Operations Management, vol. 36, no. 1, pp. 130-146, 2015.

[32] S. S. Gan, I. N. Pujawan, Suparno, and B. Widodo, "Pricing decision for new and remanufactured product in a closedloop supply chain with separate sales-channel," International Journal of Production Economics, vol. 190, pp. 120-132, 2016.

[33] J. J. Kovach, A. Atasu, and S. Banerjee, "Salesforce incentives and remanufacturing," Production and Operations Management, vol. 27, no. 3, pp. 516-530, 2018. 
[34] J. Ma, H. Ren, M. Yu, and M. Zhu, "Research on the complexity and chaos control about a closed-loop supply chain with dual-channel recycling and uncertain consumer perception," Complexity, vol. 2018, Article ID 9853635, 13 pages, 2018.

[35] J. Tang, B. Y. Li, K. W. Li, Z. Liu, and J. Huang, "Pricing and warranty decisions in a two-period closed-loop supply chain," International Journal of Production Research, vol. 58, no. 6, pp. 1688-1704, 2020.

[36] F. J. Ramírez, J. A. Aledo, and D. T. Pham, "Economic modelling of robotic disassembly in end-of-life product recovery for remanufacturing," Computers and Industrial Engineering, vol. 142, Article ID 106339, 2020.

[37] P. Brooks and H. Zank, "Loss averse behavior," Journal of Risk and Uncertainty, vol. 31, no. 3, pp. 301-325, 2005.

[38] D. Kahneman and A. Tversky, "Choices, values and frames," American Psychologist, vol. 39, no. 4, pp. 341-350, 2000.

[39] P. Heidhues and B. Koszegi, The Impact of Consumer Loss Aversion on Pricing, CEPR Discussion Papers (SP II 2004-17), London, UK, 2005.

[40] G. Kotonya, S. Lock, and J. Mariani, "Loss aversion and consumption choice: theory and experimental evidence," American Economic Journal: Microeconomics, vol. 7, no. 2, pp. 101-120, 2012.

[41] S. H. Kim and J. Lee, "Firm behavior under consumer loss aversion," Social Science Electronic Publishing, vol. 27, no. 2, pp. 171-186, 2014.

[42] R. Antonio, "Selling substitute goods to loss-averse consumers: limited availability, bargains and rip-offs," The RAND Journal of Economics, vol. 47, no. 3, pp. 709-733, 2016.

[43] S. Fabrizi, S. Lippert, C. Puppe, and S. Rosenkranz, "Manufacturer suggested retail prices, loss aversion and competition," Journal of Economic Psychology, vol. 53, pp. 141-153, 2016.

[44] O. März, "Competitive persuasive advertising under consumer loss aversion," Economics Letters, vol. 185, Article ID 108690, 2019.

[45] C. Ghesla, M. Grieder, and M. Stadelmann, "Pro-environmental incentives and loss aversion: a field experiment on electricity saving behavior," Energy Policy, vol. 137, Article ID 111131, 2020.

[46] Z. Liu, K. W. Li, B.-Y. Li, J. Huang, and J. Tang, "Impact of product-design strategies on the operations of a closed-loop supply chain," Transportation Research Part E: Logistics and Transportation Review, vol. 124, pp. 75-91, 2019.

[47] B. Köszegi and M. Rabin, "A model of reference-dependent preferences," Quarterly Journal of Economics, vol. 121, no. 4, pp. 1133-1165, 2006.

[48] A. Tversky and D. Kahneman, "Advances in prospect theory: cumulative representation of uncertainty," Journal of Risk and Uncertainty, vol. 5, no. 4, pp. 297-323, 1992.

[49] B. G. S. Hardie, E. J. Johnson, and P. S. Fader, "Modeling loss aversion and reference dependence effects on brand choice," Marketing Science, vol. 12, no. 4, pp. 378-394, 1993.

[50] V. Köbberling and P. P. Wakker, "An index of loss aversion," Journal of Economic Theory, vol. 122, no. 1, pp. 119-131, 2005.

[51] L. P. Metzger and M. O. Rieger, "Non-cooperative games with prospect theory players and dominated strategies," Games and Economic Behavior, vol. 115, pp. 396-409, 2019.

[52] R. Giutini and K. Gaudette, "Remanufacturing: the next great opportunity for boosting us productivity," Business Horizons, vol. 46, no. 6, pp. 41-48, 2003.

[53] S. Bernard, "Remanufacturing," Journal of Environmental Economics and Management, vol. 62, no. 3, pp. 337-351, 2011.
[54] C. F. Camerer, "Behavioral economics," Current Biology, vol. 24, no. 18, pp. R867-R871, 2014.

[55] X.-X. Zheng, D.-F. Li, Z. Liu, F. Jia, and J.-B. Sheu, "Coordinating a closed-loop supply chain with fairness concerns through variable-weighted Shapley values," Transportation Research Part E: Logistics and Transportation Review, vol. 126, pp. 227-253, 2019.

[56] O. Samuel, "Loss aversion and market crashes," Economic Modelling, vol. 92, pp. 70-86, 2020. 